\title{
Konuşma Sesi Bozukluklarının Düzeltilmesine Yönelik Eğitim Platformu Tasarımı
}

\author{
Ayça AK*, Ali SARIKAŞ, Ayşe YAYLA \\ Elektronik ve Otomasyon Bölümü, Marmara Üniversitesi, İstanbul, Türkiye \\ aycaak@marmara.edu.tr, ali.sarikas@marmara.edu.tr, acetinkaya@marmara.edu.tr \\ (Geliş/Received:12.06.2016; Kabul/Accepted:29.06.2017)
}

DOI: $10.17671 /$ gazibtd.330867

\begin{abstract}
Özet- Konuşma sesi bozuklukları bireylerin akademik ve sosyal çevrelerinde psikolojik sorunlar yaşamasına neden olabilmektedir. Dil ve konuşma terapistlerinden profesyonel destek alan bireylerin bu kusuru düzeltmeleri mümkün olmasına rağmen, terapinin kısa sürede olumlu sonuçlar vermesi daha çok bireylerin kendi çabalarına bağlıdır. Terapistlerin bireylere ayırdıkları zamanın kısıtlı olması da göz önüne alındığında bireysel çalışmaların önemi artmaktadır. Bu çalışmada, EasyVR konuşma tanıma modülü Arduino Uno ile bütünleştirilerek bir ses işleme konuşma tanıma sistemi oluş̧urulmuştur. C\# nesne yönelimli programlama dili kullanılarak kullanımı kolay Türkçe bir eğitim platformu hazırlanmıştır. Böylece bireylerin istedikleri zaman ve ortamda çalışmalarını gerçekleştirmelerine olanak sağlanmıştır. Sistem " $r$ " sesinin artikülasyon probleminin düzeltilmesine yönelik olarak 3 zorluk seviyesinde 30 kelime ile test edilmiştir. 30 kişi üzerinde yapılan testler sonucunda, " $r$ " sesi iyileştirme süreçlerinin bu eğitim platformu ile desteklendiğinde hızlandığı gözlenmiştir.
\end{abstract}

Anahtar Kelimeler - Artikülasyon Bozukluğu, Konuşma Tanıma, EasyVR, Arduino.

\section{Training Platform Design for Correction of Speech Sound Disorders}

\begin{abstract}
Articulation disorders can cause psychological problems in their academic and social environment of individuals. Although individuals who receive professional support from language and speech therapists are able to correct these malpractices, it is more likely that the therapy will give positive results in a short time to the individual's own efforts. Considering the limited therapy time, importance of individual efforts increases. In this paper, a sound processing system has been designed via integrating EasyVR speech recognition module with Arduino Uno shield. A user-friendly Turkish training platform has been improved by using object-oriented $\mathrm{C} \#$ programming language. Thus, it is possible for individuals to carry out their work in the time and place they desire. The system has been tested with 30 words at 3 difficulty levels to correct the articulation problem of "r" sound. As a result of tests over 30 people, it was observed that the "r" sound correcting processes were accelerated when supported by this training platform.
\end{abstract}

Keywords - Articulation disorder, speech recognition, EasyVR, Arduino.

\section{GİRIŞ (INTRODUCTION)}

Konuşma sesi bozukluğu, konuşmanın akıcılı̆̆ında, ritminde, vurgularında, zihinsel organizasyonunda sorunların olmasıdır. Konuşma, fiziksel ve zihinsel bir süreç olduğundan pek çok etken konuşma bozukluklarına sebep olabilir. Bir başka ifade ile konuşma sesi bozukluğu, dil kazanımıyla ilgili olabileceği gibi tıbbi ve psikolojik pek çok etkenden de kaynaklanabilir. Bundan dolayı konuşma bozukluğunun giderilmesi, disiplinler arası çalışmalar veya farklı disiplinlerin yaptığ araştırmalardan hareketle mümkündür.
Konuşma sesi bozukluklarından biri olan artikülâsyon bozukluğu; sesin düşürülmesi veya atlanması, ses eklemesi, sesin değiştirilmesi ve sesin bozulması şeklinde dört farklı şekilde ortaya çıkmaktadır [1]. (i) Sesin düşürülmesi veya atlanması, kelimelerde bazı seslerin hiç yokmuş gibi söylenmesidir. Bu kusur, bazı yöresel özelliklerden kaynaklanabilir. Örnek, "saat" kelimesinin "sat", "yalan" kelimesinin "alan", "yemek" kelimesinin "imek", "hava" kelimesinin "ava", "bir dakika" kelimelerinin "bi dakka", "hanımefendi" kelimesinin "hamfendi" olarak söylenmesi. (ii) Ses eklenmesi, kelimede veya ekte olmayan bazı seslerin kelime veya ekin o şekildeymiş gibi söylenmesidir. İki ünlü veya ünsüzün arasına ses eklemekle ortaya çıkmaktadır. Örnek, 
"saat" kelimesinin "sahat", "lazım" kelimesinin "ilazım", "yazarken" kelimesinin "yazarkene" şeklinde söylenmesi. (iii) Sesin değiştirilmesi, en sık görülen ses kusurudur. Özellikle "r" ve "s" seslerinin sıklıkla yanlış telaffuz edildiği görülmektedir. " $r$ " seslerinin sıklıkla " $y$ " bazen de "l" şeklinde telaffuz edildiği görülmektedir. Bu tür bozuklukları tedavi etmek çoğu zaman mümkünken bazen kalıcı da olabilmektedir. Bazı çocukların ilk okuma yazmayı öğrendikten sonra sesin ve harfin farkına varmasıyla bu sorunu çözdükleri de görülmektedir. Fakat bu durumda " $y$ " leri " $r$ " olarak seslendirdikleri de görülmektedir. Bunun için de çocuklara okuma çalışmaları çokça yaptırılmalı ve çocukların kelimelerde sesin varlığını algılamaları sağlanmalıdır. Fonetik farkındalığın oluşturulması ile birlikte görsel algılamanın sağlanmasıyla belli bir dönemden sonra sesleri doğru şekilde telaffuz etmeleri sağlanacaktır. Kelimelerin yanlış öğrenilmesiyle de ses değiştirme yanlışlıkları olmaktadır. Örnek, "köprü” kelimesinin "körpü”, "herkes" kelimesinin "herkez", "kamyon" kelimesinin "kaymon" olarak söylenmesi. (iv) Sesin bozulması, mahallî söyleyişlerden kaynaklanan bir kusurdur. Özellikle "k" ve "h" seslerinin boğazdan telaffuzu çoğu ağızlarda görülen bir durumdur.

Artikülâsyon bozukluğunda en sık karşılaşılan nedenlerden biri de işitme engelidir. İşitme engelli bireylerin konuşma sesi bozukluğunu düzeltmek için Kröger ve ark. [2] sesli ve görsel geri bildirim sağlayan yazılım geliştirmişlerdir. Standart Alman telaffuz kalitesine ulaştırmak için akustik ve konuşma sesi açısından önem arz eden yerler görsel olarak belirtilerek bu eğitim metodunun bu alanda önceden yapılmış çalışmalar kadar yararlı ve verimli olduğunu göstermişlerdir.

$\mathrm{Bu}$ çalışmada, artikülasyon bozukluklarını düzeltmeye yönelik yeni bir Türkçe yazılım platformu geliştirilmiştir. Sistem kullanıcının " $\mathrm{r}$ " sesi içeren kelimeleri kendi kendine çalışabileceği eğitim ve başarımını ölçebileceğ test bölümlerinden oluşmaktadır.

\section{ARTİKÜLASYON BOZUKLUKLARINA YÖNELIK YAZILIMLAR (SOFTWARES FOR ARTICULATION DISORDERS)}

Dünyada son 10 yıl içerisinde yapılan araştırmalar, daha çok yabancı dil öğretimi için bilgisayar destekli telaffuz öğretimi çalışmalarına hız verildiğini ve yabancı dil öğretim etkinliklerinde, bireylere doğru telaffuz becerilerinin kazandırılması için yazılımların geliştirildiğini göstermektedir [3]. English Speech Training System [4], Korean Pronunciation Education System [5], Articulation Tutor (ARTUR) [6], BALDI [7], EasyLexia [8], Indiana Speech Training Aid (ISTRA) [9] bu yazılımlara örnek olarak verilebilir. Bilgisayar destekli telaffuz yazılımları, kimi çalışmalarda telaffuz eğiticisi ya da telaffuz uzmanı şeklinde de isimlendirilmektedir [10]. Bilgisayar destekli telaffuz yazılımları istenen zamanda ve yerde erişime açık olması nedeniyle daha esnek çalışabilmeyi mümkün hale getirmektedir [11]. Bilgisayar destekli telaffuz yazılımlarının, ses ve görüntü temeli üzerine yapılandırıldıkları bununla birlikte birbirlerinden, kullanıcılara sağladıkları geri dönüt biçimleriyle farklılaştıkları görülmektedir. Bazı bilgisayar destekli telaffuz yazılımları kullanıcılara telaffuzlarıyla ilgili puan verirken, bazıları da telaffuz sürecinde görevi olan organların hareketlerini göstermektedirler. BALDI ve ARTUR yazılımları burada ifade edilen konuşma eğitim sistemlerine örnek olarak verilebilir.

Konuşma aktivitelerini bilgisayar ortamında gerçekleştirebilen 3B oluşturulmuş konuşan kafa modeli BALDI profesyonel yazılımlara örnek olarak verilebilir. BALDI kafa modeli, dokusu şeffaflaştırıldığında görülebilen dil, damak ve dişlere sahiptir. BALDI, öğrencilerin etkileşim içerisinde olduğu bir rehber rolü üstlenerek öğrencilerin telaffuz becerileri ile fonolojik farkındalıklarını geliştirebilmelerinde yardımcı olmaktadır [12]. BALDI 3B konuşan kafa modeli, yazılım içinde yürütülen konuşma etkinlikleri esnasında ön, yan ve arka görüş açılarıyla izlenebilmektedir. BALDI ve benzeri yeni nesil bilgisayar destekli telaffuz yazılımları, normal konuşma esnasında görselleştirilemeyen ağız içi yapıları görünür kılabilmeleriyle, konuşma aktivitelerinde duyuşsal eksikliği bulunan, konuşma güçlüğü çeken ve zorlanan bireylerin bu problemlerini giderebilme konusunda büyük bir potansiyele sahiptirler [13]

ARTUR, Royal Institute of Technology (Stockholm, İsveç) merkezinde Engwall ve arkadaşları tarafindan geliştirilmiştir. ARTUR yazılımı, doğru sonuca ulaşabilmeleri için telaffuz sürecinde etkin görev alan yüz ve ağız içi yapıların 3B (üç boyutlu) animasyonlarını bireylere geri bildirim biçiminde sunan bilgisayar destekli konuşma eğitimi sistemidir. ARTUR sisteminin en önemli özelliği, kullanıcılara telaffuz becerilerini nasıl geliştirebilmeleri gerektiği ile ilgili net geri bildirimler sunabilmesi ve konuşma esnasında görülemeyen ağız içi yapıların görülebilmesine olanak vermesidir [14]. ARTUR yazılımı içindeki 3B sanal kafa modeli üzerinde bireyin yapması gereken görsel olarak ifade edebilmekte ve modele ait dudak, dil ve sesin hareket yollarının rahatça görebileceği ekran çıktıları sunulmaktadır. Dil, damak ve çene modelleri manyetik rezonans görüntülerine (MRI) dayanmaktadır. Yeni nesil bilgisayar destekli telaffuz yazılımları, bireylere bir öğretmen gibi rehberlik yapabilmekte ve zaman sınırlaması olmadan telaffuz etkinliklerinin yürütülmesine izin vermektedir. $\mathrm{Bu}$ yazılımların ortak yanları yüzdeki dudak, çene ve kas gibi yapıların hareketlendirilebildiği 3B sanal kafa modeli ile telaffuz sırasında bireyler tarafindan görülemeyen ağız içi artikülâsyon organlarının görülebilmesine olanak vermeleridir [15].

Şimşek ve Karal, BDİT öğretim yazılımını buradan yola çıkarak geliştirmişlerdir. Geliştirilen BDİT öğretim yazılımında ilk olarak Autodesk Maya 8.0 programı kullanılarak fonetik seslerin modelleneceği "Audiovisual Language Pronunciation Instrument" (ALPI) 3B sanal 
kafa modellenmiştir. Daha sonra bu model üzerinde İngilizce fonetik seslerin modellemeleri yapılmıştır [3].

Yukarıda da bahsedildiği gibi, dünyada bilgisayar teknolojilerine dayalı yeni nesil telaffuz yazılımlarının daha çok ikinci veya daha fazla yabancı dil öğretimine yönelik geliştirildiği görülmüştür. Yapılan araştırmalar; Türkçenin gelişip zenginleşmesi için çalışan tüm kurumlar ve bireyler tarafından sesbilgisi, sesbilim, dilbilgisi, dilbilim, anlambilim gibi birçok alanda özenli ve verimli çalışmalar yürütüldüğünü ve bu alanda başvurulabilecek özgün yapıtların ortaya koyulduğunu göstermiştir. Ancak Türkçe için konuşma eğitimi alanında kullanıma sunulmuş söz konusu sistemleri temel alan sınırlı sayıda çalışma yer almaktadır.. Bu çalışmada buradan yola çıkılmıș ve artikülâsyon eğitimine yönelik bir yazılım geliştirilmiştir.

\section{SİSTEM TASARIMI (SYSTEM DESIGN)}

Sistemin donanımsal bileşenleri EasyVR konuşma tanıma modülü, Arduino Uno, mikrofon ve bilgisayardan oluşmaktadır. EasyVR' nin bilgisayara bağlantısı Arduino Uno üzerinden sağlanmaktadır. Ses kaydı EasyVR konuşma tanıma modülü üzerinde yer alan mikrofon aracılığıyla gerçekleştirilir. Sistemin blok diyagramı Şekil 1 'de gösterilmiştir.

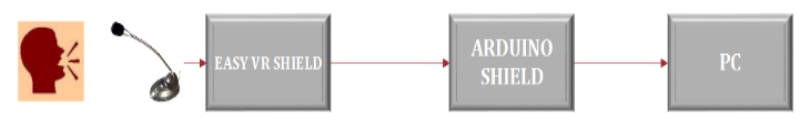

Şekil 1. Sistemin blok diyagramı

(Block diagram of the system)

Şekil 2'de sistemi oluşturan bileşenlerin birbirleriyle bağlantısının gerçek görüntüsü verilmiştir.

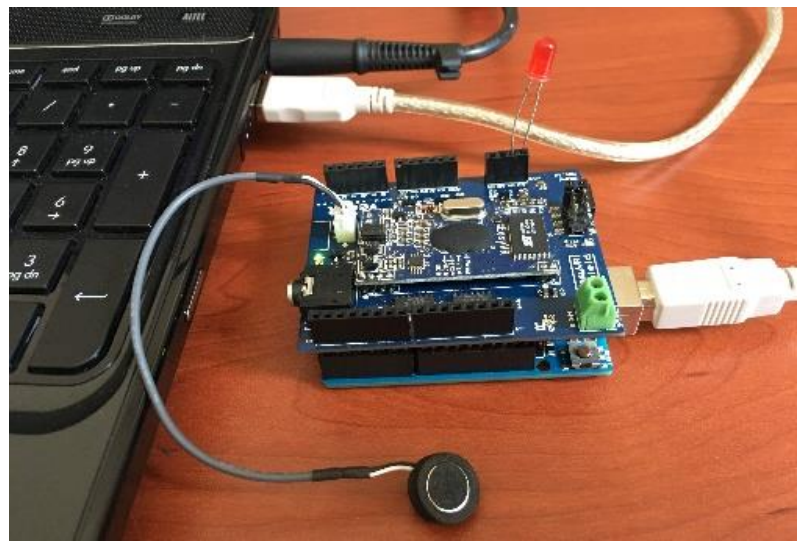

Şekil 2. Sistem bileșenleri (System components)

\subsection{EasyVR Konuşma Tanıma Modülü (EasyVR Speech Recognition Module)}

EasyVR modülü 26 adet konuşmacıdan bağımsız ve 32 adet konuşmacı tanımlı, her biri maksimum 5 saniye olan sesli kelime için eğitilebilmektedir. Konuşmacıdan bağımsız kelime seti İngilizce, Almanca, İtalyanca ve Japonca olmak üzere 4 dilde destek vermektedir. Kullanıcı tanımlı kelimeler ise istenilen dilde tanımlanabilir. Modül ile haberleşmek için seri bağlantı gerekmektedir. EasyVR modülü seri haberleşmede 9600115200 baud arası hızı desteklemektedir. EasyVR modülü 3.3V $-5 \mathrm{~V}$ arasındaki gerilim ile çalışmaktadır. Şekil 3' te EasyVR konuşma tanıma modülü ile Arduino arasındaki bağlantı görülmektedir.

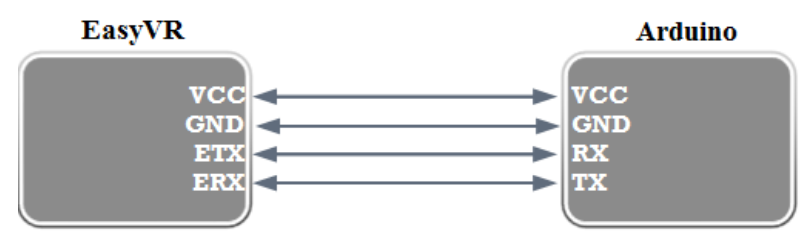

Şekil 3. EasyVR konuşma tanıma modülü - Arduino Uno bağlantısı

(Connection between EasyVR speech recognition module and Arduino Uno)

Arduino programında Arduino - EasyVR arası yapılan seri port haberleşme kodu aşağıda görülmektedir.

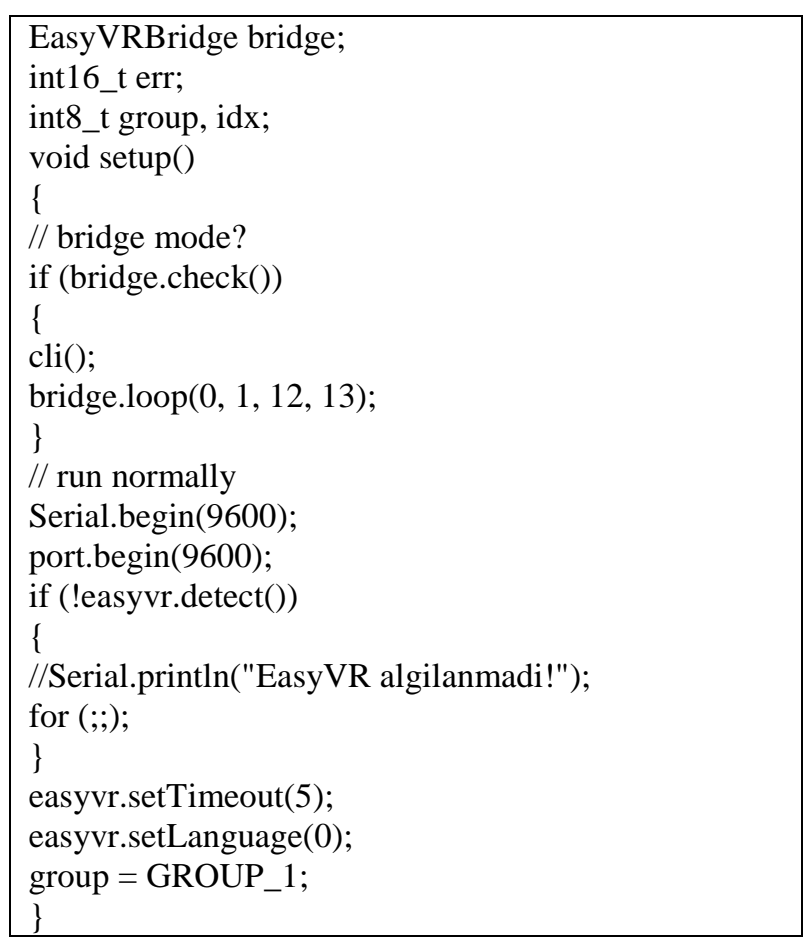

Şekil 4'teki 1 numaralı bölümde, EasyVR modülünün bilgisayara hangi seri porttan bağlandığı seçilir. 2 numaralı bölüm, grup numaralarının olduğu, tanımlanacak kelimelerin girileceği bölümdür. 


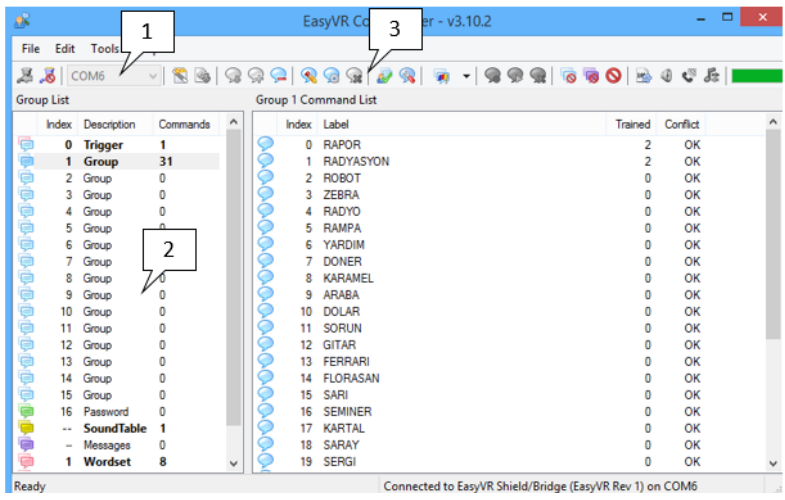

Şekil 4. EasyVR komut ara yüzü (EasyVR Commander Interface)

15 adet gruptan hangisinde kelime tanımlanmışsa, Arduino ile EasyVR modülü arasında bağlantı kurulduğunda o grup numarası ile haberleşme yapılacaktır. 3 numaralı bölümde yeni bir kelime eklemek, eklenilen kelimeye isim vermek, ismini değiştirmek ve eklenen kelimeyi EasyVR modüle tanıtmak için kullanılan butonlar yer almaktadır [16].

Yeni sesler Şekil 4' te görülen EasyVR modülü ara yüzü üzerinden kaydedilir. Öncelikle EasyVR kelime ortamı açılır. EasyVR Shield ile Arduino Shield arasında seri haberleşme bağlantısı sağlanır. İstenilen gruba toplam 32 adet indekse yerleştirilecek sesler belirlenir. Kayıt edilen bu sesler iki aşamada eğitilir (Şekil 5). EasyVR kelime ortamı kapatılır.

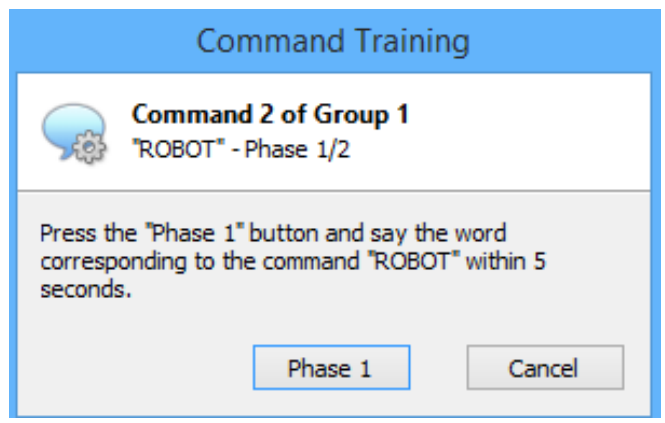

Şekil 5. EasyVR komut ara yüzünde kelimelerin eğitilme aşaması

(Training stage of words on EasyVR Commander)

3.2. Visual Studio ile Kullanıcı Ara yüzü (User Interface with Visual Studio)

"r" konuşma sesi bozukluğunun düzeltilmesine yönelik olarak geliştirilen eğitim platformunun tasarımında, C\# nesne yönelimli programlama dili kullanılmıştır. C\# programlama dili kullanılarak geliştirilen uygulamaya ait akış diyagramı Şekil 6 'da görülmektedir.

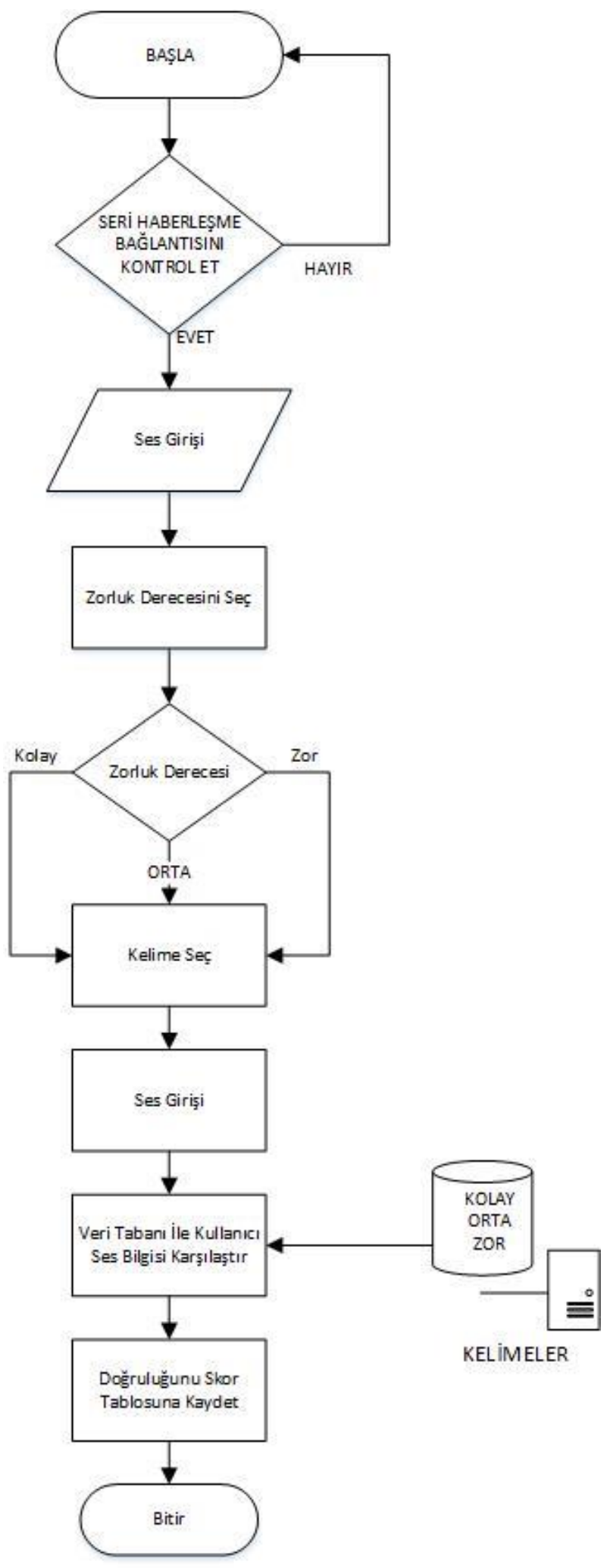

Şekil 6. Akış diyagramı (Flow chart)

Şekil 7'de giriş sayfası görülmekte olan ara yüz üzerinden kullanıcı kullanma talimatları menüsü ile programı nasıl kullanacağını, skorlar menüsü ile yapmış olduğu testlerin 
skorlarını ve başla butonu ile de eğitim ve test menülerine erişebilmektedir.

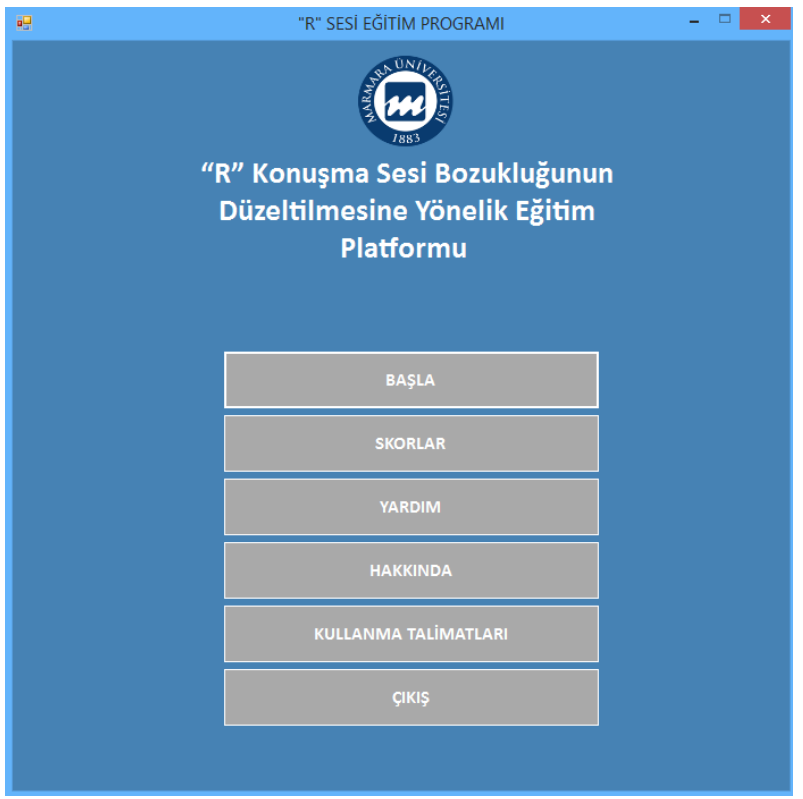

Şekil 7. Kullanıcı ara yüzünün ana sayfası (Home page of user interface)

Şekil 8'de görüldüğü gibi, "Başla" butonuna basıldıktan sonra ekrana gelen E Ĕgitim bölümünde kelimeler, zorluk derecelerine göre "Kolay, Orta, Zor" olarak üç bölüme ayrılmıştır [17]. Bu kelimeler " $r$ " sesinin başta, ortada ve sonda olduğu örneklerden seçilerek oluşturulmuştur. Kullanıcı istediği bir seviyeden başlayarak içerisinde " $r$ " sesi olan kelimeleri çalışabilmektedir.

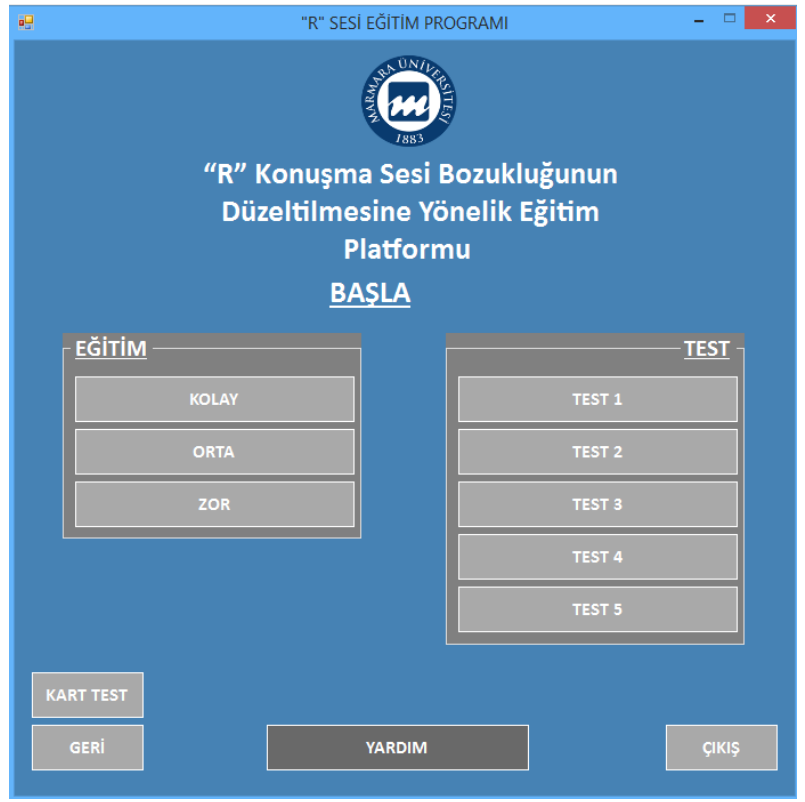

Şekil 8. Kullanıcı Ara Yüzünün eğitim ve test menüsü (Training and test menu of user interface)

Test bölümünde 5 adet test hazırlanmıştır. Bu testlerde kullanıcı istediği bir testi seçerek belirlenen kelimeleri telaffuz etmekte ve bu test sonuçları da skorlar tablosuna kayıt edilmektedir. Kullanıcı test kelimelerinden kaç tanesini doğru söylediğini bu tablodan görebilmektedir. Şekil 9'da test ekranına ait ara yüz görülmektedir.

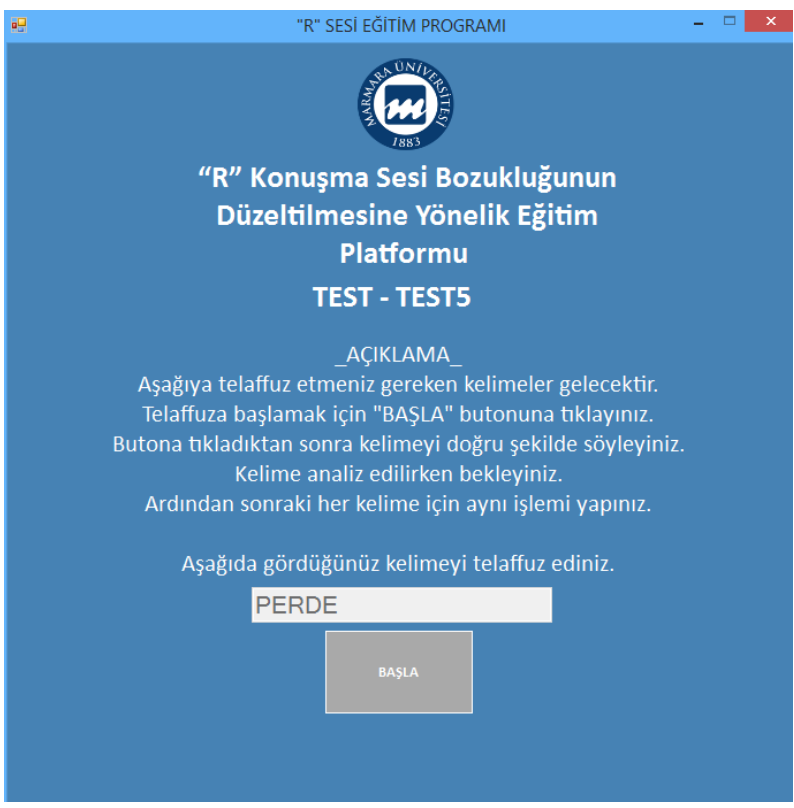

Şekil 9. Kullanıcı ara yüzü test menüsü (Test menu of user interface)

\section{SONUÇLAR VE TARTIŞMA (RESULTS AND DISCUSSION)}

İnsanların günlük yaşamını olumsuz etkileyen konuşma sesi bozukluklarından, "r" sesi artikülasyon bozukluğu "r" sesinin siklıkla "y" bazen de "l" şeklinde telaffuz edilmesine sebep olmaktadır. Bu tür konuşma bozukluğu, sosyal, duygusal, akademik ya/ya da iş hayatını olumsuz yönde etkilemektedir. Bu sorunu düzeltmek için hem uzman yardımıyla dil ve konuşma bozuklukları alanında eğitim, araştırma ve uygulama merkezlerinden, hem de bilgisayar destekli uzman sistemlerden yararlanılmaktadır.

$\mathrm{Bu}$ tür sorunları yaşayan bireyler konuşma terapistlerinden profesyonel destek almaktadırlar. Ancak bireysel çalışma süreçleri yetersiz kalmaktadır. $\mathrm{Bu}$ konuda geliştirilmiş mevcut programlar, daha ziyade İngilizce ve diğer yabancı diller için mevcuttur. Türkçe desteği olmayan bu programlar bireysel kullanıma da elverişli değildir.

Artikülasyon bozukluklarını düzeltmeye yönelik çalışma kapsamında geliștirilen platform, kullanımı kolay ve bireysel çalışmalara elverişlidir. En sık karşılaşılan artikülasyon bozukluğu " $r$ " sesini söyleyememe olduğundan, bu platformun deneme aşamasında örnek ses olarak " $r$ " sesi seçilmiștir. Prototip olarak geliştirilen bu sistemin kullanıcılar üzerinde etkisini incelemek için daha farklı artiküsyon problemleri ve daha fazla birey üzerinde testler yapılarak geliştirilmesi planlanmaktadır. 
Konuşma terapistinin gözetiminde doğru olarak telaffuz edilen sesler kayıt altına alınarak, eğitim ve test aşamasında bu kelimeler kullanıcının ifade ettiği kelimelerle karşılaştırılmaktadır. Kullanıcının yanlış ifade etmesi durumunda, terapistin uygun gördüğü doğruluğa ulaşana kadar, kullanıcı kelimeyi tekrarlayacaktır.

Kullanıcının istediği herhangi bir ortamda bu platform aracılığı ile, sınırsız sayıda pratik yapması, gördüğü terapi sürecini kısaltmaya yönelik olumlu bir katkı sağlayacağı öngörülmektedir.

Yaş ve cinsiyete bağlı olarak ses frekansları farklılık gösterdiğinden, test edilecek seslerin de aynı cinsiyet ve yaş grubundaki bireylerden seçilmesi faydalı olacaktır. Sessiz ortamlarda, diş etkenlerden uzak ve parazitsiz ses kaydıyla daha iyi sonuçlar alınmıştır. Her bir birey yaptığ 1 çalışmaların sonuçlarını skor tablosu olarak görebilmektedir.

Sistem 30 kişi üzerinde test edilmiştir. R artikülasyon problemi yaşamayan kişiler kolay, orta ve zor seviyeli kelimeleri ilk denemelerinde doğru telaffuz etmișlerdir. Artikülasyon problemi yaşayan kişilerde kolay kelimelerde doğruluk oranı ortalama \%90'a ulaşmıştır. Bu bireylerde bir veya ikinci denemelerinde doğru telaffuz etmeye başlamışlardır. Orta zorluktaki kelimelerde doğruluk oranının biraz düştüğü ve doğru telaffuz için deneme sayısının üç veya dörde çıktığı gözlenmiştir. R sayısının ve hece sayısının arttığı zor seviyeli kelimelerde ise, doğru telaffuza ulaşmak için yapılan deneme sayısının arttığı belirlenmiştir.

$\mathrm{Bu}$ çalışmanın, konuşma sesi bozukluklarının düzeltilmesine yönelik, kullanımı kolay, yeni ara yüz yazılımlarının geliştirilmesine katkı sağlayacağı öngörülmektedir.

\section{TEŞEKKÜR (ACKNOWLEDGEMENT)}

$\mathrm{Bu}$ projenin hazırlanmasında emeği geçen Oğuz DEMIRHAN, Emre ARABACI, Berkay CINOL, Erhan KANLICA, M. Doğukan ÖZGAN'a ve değerli yönlendirmeleri için Uzman Dil ve Konuşma Terapisti Sayın Zehra Yılmaz EKSEN'e teşekkür ederiz.

\section{KAYNAKLAR (REFERENCES)}

[1] İ. Özgür,, Konușma Bozuklukları ve Sağaltımı, Nobel Kitabevi, Adana, 2003

[2] B. J. Kröger, P. Birkholz, R. Hoffmann, H. Meng, “Audiovisua Tools for Phonetic and Articulatory Visualization in Computer-Aided Pronunciation Training", Lecture Notes in Computer Science, 5967 337-345.

[3] A. Șimșek, H. Karal, "ALPI İngilizce Telaffuz ve Artikülasyon Yazılımının Geliştirilmesi ve İngilizce Telaffuz Becerileri Üzerine
Etkilerinin Incelenmesi", Journal of Instructional Technologies \& Teacher Education, 3, 1, 44-60, 2014.

[4] M. Goto, S. Takata, Y. Uekawa, "Micro-processor based English speech training system", IEEE Transactions on Consumer Electronics, vol.34, no.3, pp 824-834, Aug .1988

[5] H.S. Kim, Y.T. Byun, K.C. Lee, “A Korean pronunciation education system in a multimedia environment", Journal of the Korea Information Science Society, vol .20, no.12, pp 1807-1814, Dec 1993.

[6] O. Bälter, O. Engwall, A.M. Öster, H. Kjellström, "Wizard-of-Oz test of ARTUR: a computer-based speech training system with articulation correction", Proceedings of the ACM SIGACCESS Conference on Computers and Accessibility, ASSETS 2005, Baltimore, MD, USA, October 9-12, 2005.

[7] Massaro, D. 1998. "Perceiving talking faces: From speech perception to a behavioral principle", Cambridge, Massachusetts: MIT Press.

[8] R. Skiada, E. Soroniati, A. Gardeli, D. Zissis, "EasyLexia 2.0 Redesigning our mobile application for children with learning difficulties", Themes in Science \& Technology Education, 7(2/3), 119135

[9] C.S. Watson, D.J. Reed, D. Kewley-Port, D. Maki, "The Indiana Speech Training Aid (ISTRA) I Comparisons between Human and Computer-Based Evaluation of Speech Quality", Journal of Speech, Language, and Hearing Research, June 1989, Vol. 32, 245-251.

[10] Internet: K. Ananthakrishnan, Computer Aided Pronunciation System (CAPS), 2003.

http://arrow.unisa.edu.au:8081/1959.8/78981 Son Erişim Tarihi: 04.06.2015

[11] H. Franco, L. Neumeyer, M. Ramos, H. Bratt, "Automatic Detection of Phone- Level Mispronunciation for Language Learning", Eurospeech 99, Budapește, 1999.

[12] D.W. Massaro, Y. Liu, T.H. Chen, C.A. Perfetti, “A Multilingual Embodied Conversational Agent for Tutoring Speech and Language Learning", Proceedings of the Ninth International Conference on Spoken Language Processing (Interspeech 2006 - ICSLP, September, Pittsburgh, PA), 825-828, Universität Bonn, Bonn, Germany, 2006

[13] Massaro, D., Cohen, M. \& Beskow, J. 1999. "From theory to practice: rewards and challenges", International Conference of Phonetic Sciences, San Francisco.

[14] Internet: J. Beskow, Talking Heads-Models and Applications for Multimodal Speech Synthesis, 2003

http://urn.kb.se/resolve?urn=urn:nbn:se:kth:diva-3561 Son Erişim Tarihi: 06.06.2015

[15] Wik, P. 2004. "Designing a virtual language tutor". Phonetic 2004, Stockholm University, Stockholm

[16] M. Aydın, Altı serbestlik derecesine sahip bir robot kolunun ses ile kontrolü, Yüksek Lisans Tezi, Marmara Üniversitesi, Fen Bilimleri Enstitüsü, 2012

[17] Zehra Yılmaz Eksen, Seyhun Topbaş, C. Kemal Eksen, "Artikülasyon ve Fonolojik Bozukluklar Terapi Seti", Maya Akademi, 2015. 